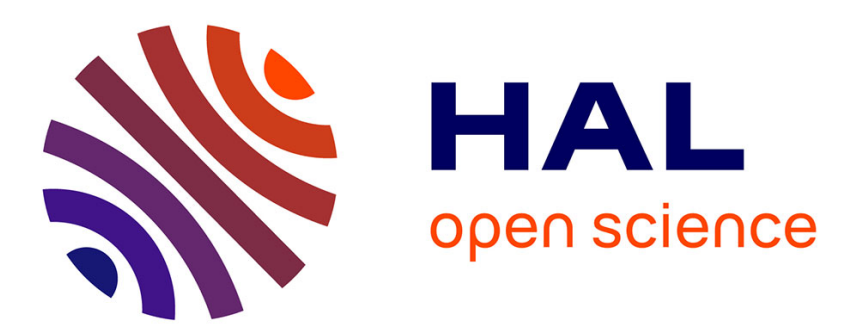

\title{
Skin localization of cow's milk proteins delivered by a new ready-to-use atopy patch test.
}

D. Soury, G. Barratt, S. Ah-Leung, P. Legrand, H. Chacun, G. Ponchel

\section{To cite this version:}

D. Soury, G. Barratt, S. Ah-Leung, P. Legrand, H. Chacun, et al.. Skin localization of cow's milk proteins delivered by a new ready-to-use atopy patch test.. Pharmaceutical Research, 2005, 22 (9), pp.1530-6. 10.1007/s11095-005-5881-4 . hal-00385449

\section{HAL Id: hal-00385449 \\ https://hal.science/hal-00385449}

Submitted on 25 May 2009

HAL is a multi-disciplinary open access archive for the deposit and dissemination of scientific research documents, whether they are published or not. The documents may come from teaching and research institutions in France or abroad, or from public or private research centers.
L'archive ouverte pluridisciplinaire HAL, est destinée au dépôt et à la diffusion de documents scientifiques de niveau recherche, publiés ou non, émanant des établissements d'enseignement et de recherche français ou étrangers, des laboratoires publics ou privés. 


\title{
Research Paper
}

\section{Skin Localization of Cow's Milk Proteins Delivered by a New Ready-to-Use Atopy Patch Test}

\author{
D. Soury,1,3 G. Barratt,1 S. Ah-Leung, 2 P. Legrand, 1 H. Chacun, 1 and G. Ponchel 1
}

Received March 29, 2005; accepted May 4, 2005

Purpose. Atopy patch tests (APTs) allow the detection of delayed allergies at the skin level. The

localization of b-lactoglobulin delivered into the skin by an innovative ready-to-use APT (E-patch) was

investigated and the efficacy and safety of this device were assessed.

Methods. The E-patch containing b-lactoglobulin was placed for $24 \mathrm{~h}$ in contact with hairless rat skin

mounted in a Franz diffusion cell. Transdermal passage was monitored by measurement of blactoglobulin

A-[methyl-14C] or by two-site enzyme immunoassay. An iterative skin stripping allowed

measurement of the b-lactoglobulin penetrating the first external skin layers.

Results. After $24 \mathrm{~h}, 92 \%$ of b-lactoglobulin remained on the skin. The iterative skin strippings showed a

135 -fold higher concentration of b-lactoglobulin in the stratum corneum than that found in the

epidermisYdermis. Analysis of the solution in the receiver compartment by radioactivity assays or

immunoassays indicates that intact protein did not cross the skin.

Conclusions. The E-patch system allows native b-lactoglobulin to concentrate in the stratum corneum,

in the vicinity of immunological cells, but does not lead to its systemic delivery. Therefore, it is suggested that this delivery system creates ideal conditions for promoting a positive topical response with reduced

risk of systemic anaphylactic reactions caused by the native form of the b-lactoglobulin A.

KEY WORDS: atopy patch test; b-lactoglobulin; delayed food allergy; milk; skin.

INTRODUCTION

Food allergy is a common problem in infants and young

children. In particular, hypersensitivity to cow's milk occurs

in $2 \mathrm{Y} 3 \%$ of infants $(1,2)$. The recommended test, or Bgold

standard $^{\wedge}$, in the diagnosis of food allergy is the double-blind,

placebo-controlled food challenge (3). New tools, such as the

patch test [atopy patch test (APT)], which provides a prolonged

contact of $48 \mathrm{~h}$ of allergen with the skin, have been

introduced for the screening and diagnosis of delayed forms

of milk allergy (4Y7).

In every allergy, there always is a first contact between

the organism and the allergen, the sensitization step, followed

by manifestations of allergy occurring after a second

contact. These manifestations are either immediate after the

contact with the allergen (less than $2 \mathrm{~h}$ ) or delayed (more

than $2 \mathrm{~h}$ ) and the site of these manifestations can be different

from the site of sensitization. Indeed, for example, in food

allergy, provoked via the gastrointestinal tractus, the manifestations

could be gastrointestinal reactions (nausea and

vomiting, diarrhea), or anaphylactic reactions, or respiratory

reactions (asthma, rhinitis), or cutaneous reactions (urticaria,

atopic dermatitis) (8).

Delayed allergy (type IV hypersensibility) is a cellular

immune response to an allergen. The first contact of the

allergen with the organism, the sensitization, is necessary.

The allergenic substance is captured by immune cells such as macrophages or Langerhans cells (in the skin). Immune cells migrate via the afferent lymphatics to the draining lymph nodes where they present allergen to T lymphocytes. An allergic response is thus induced with production of memory $\mathrm{T}$ lymphocytes. After this sensitization, when a second contact with the allergen occurs on the skin, allergen is again captured by local Langerhans cells that recruit circulating memory T lymphocytes. These lymphocytes release mediators that provoke the allergic reaction. Because this reaction occurs between 48 and $72 \mathrm{~h}$ after the second contact with the allergen, it is known as a delayed allergic reaction (9Y11). Atopy patch tests have been shown to be a valuable complementary tool in the diagnosis of food allergy in children with late-phase clinical reactions $(12,13)$. Moreover, this test has the advantages of being noninvasive and used on the skin. Indeed, the skin is at one and the same time a barrier of the organism with a local immune system and a possible route of administration via transdermal passage of drugs (14). So allergens put on the skin can come into contact with immune cells, however, at the same time, their passage 
through the skin can be limited by the very low permeability of the skin. In general, APTs are prepared with a concentrate 0724-8741/05/0900-1530/0 \# 2005 Springer Science + Business Media, Inc. 1530

Pharmaceutical Research, Vol. 22, No. 9, September 2005 (\# 2005) DOI: $10.1007 / \mathrm{s} 11095-005-5881-4$

1 Laboratoire de Physico-Chimie, Pharmacotechnie et Biopharmacie,

UMR CNRS 8612, Faculte' de Pharmacie, Universite' Paris Sud,

Tour D5, 2e 'me e'tage 5 rue J.B. Cle'ment, 92296 Cha`tenay-Malabry

Cedex, France.

2 INRA-CEA, SPI, CE Saclay, Gif-sur-Yvette, France.

3 To whom correspondence should be addressed: (e-mail: delphine.

soury (acep.u-psud.fr)

of cow's milk in a saline solution adsorbed on a blotting paper placed in an aluminum test cup of a Finn Chamber. This occlusive delivery system is intended to be prepared and secured on the skin of children by the medical practitioner. The occlusion time is $48 \mathrm{~h}$ and the results are read $24 \mathrm{~h}$ later $(1,5,15)$. However, these tests suffer from many drawbacks including the absence of standardization (13,15Y17).

To solve this problem of standardization, an innovative ready-to-use APT has been developed: the E-patch $\backslash$ system. This APT is composed of an occlusive chamber and differs from those previously described in that it is ready-to-use, with the allergen present as dry milk powder, with a defined protein content and a guaranteed protein quality. Because of skin occlusion and normal skin transepithelial water loss (TEWL) $(18,19)$, this system is intended to progressively create a solution of the proteins contained in the milk powder at the surface of the skin. Ideally, the allergens should concentrate in the epidermis to trigger a local reaction but not permeate through the skin, to avoid any possible systemic anaphylactic response.

Following application on the skin, a redness extending beyond the area under the patch is observed in the case of patients allergic to the milk. It has been described that this type of reaction, accompanied by occasional palpable infiltration or eczema, tends to grow stronger between 48 and $72 \mathrm{~h}(1,12,15,16)$. This inflammatory reaction on the skin is mainly caused by the liberation of histamine. Histamine provokes contraction of arterioles and smooth muscle fibers and dilatation of capillary blood vessels, and is produced by polynuclear basophiles and mastocytes (20). These immune cells are localized in the epidermis, particularly in the first layer of the stratum corneum. To assess the efficacy of the test, the concentration of allergen in the vicinity of immune cells, that is, in the stratum corneum, was investigated. Therefore, the objective of this study was to design an experimental model to simultaneously investigate the amount of milk proteins delivered into the skin by this E-patch $\backslash$ and the possible transdermal passage of these proteins through the skin, to assess the efficacy and safety of the device.

One particular protein has been selected for monitoring in this study: b-lactoglobulin. Cow's milk contains about 30 Y35 $\mathrm{g}$ of proteins per liter distributed between two fractions: the lactoserum, containing about $20 \%$ of soluble proteins, and the coagulum, containing about $80 \%$ of proteins in solid form (21). Major proteins of the lactoserum are b-lactoglobulin and a-lactalbumin, whereas the coagulum is composed of the casein fraction of four proteins: as1-, as2-, b-, and k-caseins. Polysensitization to several proteins is most common and all milk proteins seem to be potential allergens (21). However, b-lactoglobulin, not present in human milk, is considered to be a major allergen (22). This globular protein occurs naturally in the form of a $36-\mathrm{kDa}$ dimer, each subunit of $18 \mathrm{kDa}$ being a 162-residue polypeptide. There are two main isoforms of b-lactoglobulin, A and B, which differ by only the two amino acids 64 and 118, aspartic acid and valine in 
b-lactoglobulin A, and glycine and alanine in b-lactoglobulin $B(21)$. Because this protein is well characterized and available in both native and radiolabeled forms, it has been chosen as a marker both to study skin localization and to detect any potential transdermal passage. MATERIALS AND METHODS

Materials

b-lactoglobulin A-[methyl-14C], specific activity $29 \mathrm{mCi} /$ $\mathrm{mg}$, was obtained from ARC (St. Louis, MO, USA) via Isobio (Fleurus, Belgium). Commercial skim cow's milk powder was distributed by Re' gilait (France). The phosphate buffer solution (PBS, pH 7.4) was supplied by Sigma (St. Louis, MO, USA).

Analysis of the Purity of the Radiolabeled Solution The radiolabeled solution of b-lactoglobulin A-[methyl$\left.{ }_{14} \mathrm{C}\right]$, the solution of b-lactoglobulin $\mathrm{A}-[$ methyl-14C] mixed with $\mathrm{Re}^{\prime}$ gilait, and the solution in the receiver compartment of the Franz diffusion cell at $24 \mathrm{~h}$ were analyzed by gel electrophoresis in $20 \%$ polyacrylamide in the presence of SDS and b-mercaptoethanol. The radioactivity on the gel was counted with a Berthold linear counter (Berthold, France) and an autoradiograph of the gel was made by contact with a Kodak BioMax MR film (France).

Animals

Female hairless rats (OFA-hr/hr) used in the ex vivo permeation study were $8 Y 9$ weeks old (weighing on average $220 \mathrm{~g}$ ) and were purchased from Charles River Laboratories (Calco, Italy). Animals were housed in standard cages at room temperature on a 12-h light/dark cycle 1 week before experimentation, and standard laboratory food and water were given ad libitum.

Formulations

Although the E-patch formulation normally contains dry powder, for these experiments the patch tests contained a protein solution. This was chosen to minimize the effects of variability between the skins of rats and to compensate for a possible lack of TEWL in the ex vivo model, which in humans would have normally resulted in rapid dissolution of the milk components $(18,19)$.

Patches were composed of a disk of occlusive polymer with a surface area of $78.5 \mathrm{~mm} 2$ surrounded by a foam border $1 \mathrm{~mm}$ thick, thus forming a chamber. An adhesive laver below the foam allowed the patches to stick to the skin. For radioactivity studies, $25 \mathrm{ml}$ of a radioactive solution of b-lactoglobulin A-[methyl-14C] mixed with a solution of $\mathrm{Re}^{\prime}$ gilait milk powder in PBS was added to the patch to obtain $20 \mathrm{mg}$ of cold b-lactoglobulin and $1 \mathrm{mCi}$ of blactoglobulin A-[methyl-14C] $(34.5 \mathrm{mg})$ per patch. The final concentration of total proteins in the patch was of $8 \mathrm{mg} / \mathrm{ml}$. For experiments in which b-lactoglobulin was measured by immunoassay, $25 \mathrm{ml}$ of a solution of Re' gilait in PBS ( $8 \mathrm{mg}$ / $\mathrm{ml}$ of proteins) was added to the patch so as to obtain $20 \mathrm{mg}$ b-lactoglobulin per patch.

Diffusion Experiments

Dorsal skin was excised from hairless rats after

euthanasia by $\mathrm{CO}_{2}$ inhalation. Any subcutaneous fat was Skin Localization of Cow's Milk Proteins 1531 carefully removed with a scalpel and several pieces were cut from each specimen. Each piece of skin was mounted on a Franz diffusion cell with a surface area for passage of 64 $\mathrm{mm}$. The epidermal side of the skin was exposed to ambient conditions, whereas the dermal side was bathed with $0.01 \mathrm{M}$ phosphate buffer solution ( $\mathrm{pH} 7.4$ ) containing $0.1 \%$ sodium azide. The receiver solution was stirred continuously with a small magnetic stirring bar. Care was taken to remove any air bubbles between the underside of the skin and the solution in the receiver compartment. The temperature of the receiver 
compartment was maintained at 34-C.

After overnight equilibration, $25 \mathrm{ml}$ of radiolabeled

solution or of unlabeled milk solution was added to a patch

that was put on the epidermal surface of the skin on the cell.

A minimum of six cells were used and experiments were

carried out with sections of skin from different animals. All

experiments were carried out with occluded donor compartments.

Samples of the receiver compartment were withdrawn

at intervals for radioactivity counting and replaced by fresh

buffer. After $24 \mathrm{~h}$, the experiments were stopped and the

diffusion setup was dismantled.

Assay of Radiolabeled Markers

Before dismantling was complete, the patch and the skin

were each rinsed carefully twice with $0.2 \mathrm{ml}$ of PBS solution.

All washings were collected and assayed for radioactivity,

together with the patch. Following the rinsing procedure, the

skin was put on a filter paper on a glass plate and a piece of

adhesive tape, $1.9 \mathrm{~cm}$ wide and about $5 \mathrm{~cm}$ long, was pressed

firmly to the skin surface with a mass of $150 \mathrm{~g}$ for $15 \mathrm{~s}$. The tape was of sufficient size to cover the area of skin that was in contact with the formulation. Twelve such strippings (corresponding to the thickness of the stratum corneum) were carried out and each strip was analyzed separately for radiolabel. The remaining skin (that is, the rest of the epidermis and the dermis after stripping of the stratum corneum) and the receiver compartment solution were also assayed for radiolabel.

Radioactivity was counted in a Beckman LS 6000 TA

(France). Skin and strip samples were weighed and dissolved with Soluene (Perkin-Elmer, Coignieres, France) ( $1 \mathrm{ml}$ ), after which scintillation medium (Hionic Fluon, PerkinElmer) was added before counting. Liquid samples were counted in Ultima Gold scintillation medium (PerkinElmer). For analysis of the receiver compartment solution, an aliquot was assayed for total radiolabel and another aliquot was mixed with BSA (final concentration of BSA was $864 \mathrm{mg} / \mathrm{ml}$ in $810 \mathrm{ml}$ ), $90 \mathrm{ml}$ of Tris $1 \mathrm{M} \mathrm{SDS} 1 \%$, and $180 \mathrm{ml}$ of trichloroacetic acid (TCA) $60 \%$. This mixture was shaken and, after overnight equilibration, the mixture was centrifuged (Jouan MR 22i, France) at $734 \mathrm{~g}$ for $5 \mathrm{~min}$ and the supernatant was recovered for counting.

Results are expressed as percentage of total radioactivity counted at the end of the experiment.

Assay by Two-Site Enzyme Immunoassay

This assay was used to determine the native and denatured b-lactoglobulin in the receiver compartment (23). One aliquot was assayed for native b-lactoglobulin and another for denatured $b$-lactoglobulin. The assays were performed in 96-well microtitre plates and were based on the use of pairs of monoclonal antibodies specific for either the native form or the reduced and carboxymethylated form of b-lactoglobulin. Detection limits for the native and the reduced b-lactoglobulin in the $\mathrm{Re}^{\prime}$ gilait solution were both $0.32 \mathrm{ng} / \mathrm{ml}$.

RESULTS

Purity of the Radiolabeled "-lactoglobulin A

The purity of the radiolabeled b-lactoglobulin A was assessed by SDS-polyacrylamide gel electrophoresis of the solution of b-lactoglobulin A-[methyl-14C] in buffer and mixed with milk.

Figure 1 shows the autoradiography of radiolabeled proteins present in the solution of b-lactoglobulin A-[methyl$\left.{ }_{14} \mathrm{C}\right](\mathrm{A})$ or present in the mixture of b-lactoglobulin A-[methyl-14C] and unlabeled milk solution (B). Identical bands were found in the two solutions. Therefore, taking into account the reducing conditions of the electrophoresis, other milk components did not seem to denature or associate with 
the b-lactoglobulin A (other than by disulfide bonds). Two major bands were present: one band at $18 \mathrm{kDa}$, which corresponds to b-lactoglobulin $\mathrm{A}$, and one band at $39 \mathrm{kDa}$, which seems to be the dimer of the b-lactoglobulin A of $36 \mathrm{kDa}$. Two other minor bands were observed around 13 and $11 \mathrm{kDa}$. The origin of these minor bands is unknown. blactoglobulin A was methylated using $14 \mathrm{C}$-formaldehyde and sodium cyanoborohydride according to the procedure of Dottavio-Martin and Ravel (24) and the resulting blactoglobulin A-[methyl-14C] was purified by extensive dialysis. There are two possible explanations for the presence of the minor bands: (a) the b-lactoglobulin A used for the synthesis might not have been pure but contaminated by other proteins of the lactoserum such as a-lactalbumin (14 $\mathrm{kDa}$ ), or (b) the b-lactoglobulin A itself could have been denatured during or after radiolabeling.

To quantitate the results of autoradiography, radioactivity on the polyacrylamide gel was counted in a Berthold linear meter. The results are shown in Table I. For both Fig. 1. Autoradiography of a gel electrophoresis in $20 \%$ polyacrylamide in the presence of SDS and b-mercaptoethanol of the solution of b-lactoglobulin A-[methyl-14C] alone (A) or mixed with unlabeled milk (B). Molecular weights were calculated from the position of standard markers run in parallel.

1532 Soury et al.

solutions, the band corresponding to b-lactoglobulin represented about $78 \%$ of the total radioactivity, with the dimer about $18 \%$, and the low-molecular-weight traces less than $4 \%$. Hence, even if contaminants or impurities are present in the radioactive solution, they only represent a low percentage of the components of the solution.

Localization and Concentration of "-lactoglobulin A-[methyl-14C] in Hairless Rat Skin

Figure 2 shows the distribution of the b-lactoglobulin A-[methyl-14C] between the different compartments of the model after $24 \mathrm{~h}$. The amount of radioactivity within the stratum corneum was determined by analyzing the 12 first tape strippings of this surface, whereas the amount of radioactivity penetrating the deeper skin strata was determined by analyzing the remainder of the full thickness skin, i.e., the rest of the epidermis and the dermis. About $92 \%$ of the radioactivity remained on the skin under the patch. The rest of the radioactivity was approximately equally distributed between the two skin layers and the receiver compartment.

The thickness of the two skin layers $(18.4 \mathrm{~T} 0.5 \mathrm{~mm}$ for the stratum corneum and $2.07 \mathrm{~T} 0.07 \mathrm{~mm}$ for the rest of the skin) (25), the volume under the patch $(78.5 \mathrm{~mm} 3)$, and the volume of the receiver compartment $(11 \mathrm{ml})$ were used to calculate the concentration of $b$-lactoglobulin $A$ in each location. b-lactoglobulin A was essentially sequestered in the stratum corneum: it was 1.6 times more concentrated than under the patch on the skin and 135 times more than in the rest of the skin (epidermisYdermis) (Fig. 3).

Figure 4 illustrates the distribution of b-lactoglobulin A-[methyl-14C] in the 12 first layers of the epidermis, which comprise the stratum corneum. Most were found in the two first strips, 1 and $0.5 \%$, respectively, representing about $58 \%$ of the total radioactivity counted in the stratum corneum. Starting from the third strip, the amount of radioactivity decreased with about $8 \%$ of the total radioactivity in the stratum corneum in each strip until the sixth strip. Thereafter, radioactivity was about $2 \%$ per strip of the total radioactivity in the stratum corneum.

Lack of Passage of Intact "-lactoglobulin Across Hairless Rat Skin

The percentage of total $b$-lactoglobulin A-[methyl-14C] detected in the receiver compartment solution was followed 
Table I. Distribution by Percentage of Total Radioactivity in the Solution of "-Lactoglobulin A-[methyl-14C] in Buffer ("-lactoglobulin A) (A) or Mixed with Unlabelled Milk

("-Lactoglobulin A in Milk) (B)

(A) "-Lactoglobulin

$A(\%)$

(B) "-Lactoglobulin

A in milk $(\%)$

Monomer (18 kDa) 78.7 77.5

Dimer (39 kDa) 17.718 .8

High molecular

weight $(>51 \mathrm{kDa})$

1.22 .1

Low molecular

weight $(<13 \mathrm{kDa})$

2.31 .6

Results were obtained after separation of the proteins on a $20 \%$ polyacrylamide gel in the presence of SDS and "-mercaptoethanol and integration of the measurement of radioactivity by a Berthold linear meter.

Fig. 2. "-Lactoglobulin A-[methyl-14C] distribution in the different compartments of the experimental setup after $24 \mathrm{~h}(\mathrm{n}=3)$. The total amount of $b$-lactoglobulin $A-[$ methyl- $14 \mathrm{C}]$ reached $100 \%$ at the end of the experiment after $24 \mathrm{~h}$. This total is composed of four parts: first, the b-lactoglobulin A-[methyl-14C] found on the patch and on the skin (patch); second, that found in the 12 first stripped layers of the skin corresponding to the stratum corneum of the epidermis (strippings); third that found in the rest of the nonstripped epidermis and in the dermis (epidermisYdermis); finally, that found in the receiver compartment, i.e., that which has crossed the skin (receiver compartment). The percentage of radioactivity counted in the receiver compartment seemed to be very high for a protein and was probably not due to the presence of intact b-lactoglobulin A-[methyl-14C]. This was demonstrated by subsequent experiments. Fig. 3. "-Lactoglobulin A concentration in the different compartments of the experimental setup after $24 \mathrm{~h}(\mathrm{n}=3)$. Results are

obtained by the supposition of the presence of about $20 \mathrm{mg}$ of cold blactoglobulin $A$ in the radioactive milk solution added to the patch at

the beginning of the experiment. These concentrations were calculated

after $24 \mathrm{~h}$ in four different compartments: first, under the patch and on the skin in a volume of $78.5 \mathrm{~mm}$ (patch); second, in the 12 first stripped layers of the skin which correspond to the stratum corneum of the epidermis whose thickness is of $18.4 \mathrm{~T} 0.5 \mathrm{~mm}$ (stratum corneum); third, in the rest of the nonstripped epidermis and in the dermis whose total thickness is $2.07 \mathrm{~T} 0.07 \mathrm{~mm}$ (epidermisYdermis); and finally in the receiver compartment of $11 \mathrm{ml}$ (receiver compartment).

Skin Localization of Cow's Milk Proteins 1533

for $24 \mathrm{~h}$. This increased linearly with time (data not shown) and after $24 \mathrm{~h}$, the percentage of b-lactoglobulin A-

[methyl-14C] detected was about $3.4 \mathrm{~T} 0.1 \%$. For each sample, after precipitation of proteins by TCA, the supernatant (representing low-molecular-weight radioactive material) accounted for approximately $97 \%$ of the radioactivity of the receiver solution. Therefore, it could be calculated that the intact b-lactoglobulin A-[methyl-14C] in the receiver was less than $0.1 \%$ of the total radioactivity added to the donor compartment. Moreover, enzyme immunoassay of the receiver solution revealed that neither intact nor denatured b-lactoglobulin could be detected. When taking into account the detection limit of the assay, this means that less than $0.02 \%$ of the protein crossed the skin. Indeed, polyacrylamide gel electrophoresis of the solution of the receiver compartment of the Franz diffusion cell did not reveal the presence of a band of b-lactoglobulin A at $18 \mathrm{kDa}$. The results obtained after acid precipitation of the receiver phase and by immunoassay and electrophoresis suggest that radioactivity in the receiver compartment did not represent intact protein but rather fragments or impurities. Therefore, no apparent permeability coefficient could reasonably be calculated for $b$-lactoglobulin $\mathrm{A}$.

DISCUSSION 
There is already considerable evidence in the literature that proteins and peptides applied to bare skin can provoke systemic immune responses, leading to the proliferation of specific T cells of both Th1 and Th2 phenotypes and the production of $\mathrm{IgG}$ and IgA antibodies $(26,27)$. Proteins as large as tetanus toxoid ( $150 \mathrm{kDa}$ ) and bovine serum albumin $(68 \mathrm{kDa})$ can be used as immunogens in this way, especially when cholera toxin, itself a protein of $68 \mathrm{kDa}$, is used as an adjuvant (28). Furthermore, a specific circulating IgE response to ovalbumin ( $45 \mathrm{kDa}$ ) has been obtained after its application onto non-sensitized animal skin (29). All this evidence indicates that sufficient numbers of protein molecules are able to reach the Langerhans cells present in the epidermis. Langerhans cells are crucial for the development of cutaneous immune responses to allergens (10). They play a role in the sensitization and manifestation of delayed allergy. Following topical exposure to sensitizing chemicals, Langerhans cells capture the allergen and are induced to migrate from the skin, via the afferent lymphatics, to the draining lymph nodes. They are therefore essential for the effective presentation of topical allergens to $\mathrm{T}$ lymphocytes and the induction of allergic responses. After a second contact, Langerhans cells capture allergen and recruit $\mathrm{T}$ lymphocytes to induce a local allergic reaction $(10,11)$.

None of the studies of transdermally induced immune responses mentioned above have attempted to localize the antigens within the skin. The present study suggests that blactoglobulin A concentrated in the stratum corneum.

About $92 \%$ of the radioactivity remained on the surface of the skin after $24 \mathrm{~h}$, but $3 \%$ was recovered in the 12 strips corresponding to the stratum corneum. This represents a significant concentration of radioactivity within this compartment. A similar accumulation of radioactivity in the stratum corneum was observed when radioactive IFN-a was applied to hairless guinea pig skin (30). In the present study, preliminary experiments have shown that the purity of the radiolabeled b-lactoglobulin A was high $(>96 \%)$ but that minor impurities could have crossed the skin. Moreover, no metabolism of the b-lactoglobulin A occurring in the skin could be detected. Therefore, it could be suggested that native b-lactoglobulin A accumulated in the vicinity of Langerhans cells and other immune cells, making it possible to induce an immune reaction. It is very likely that low or very low amounts of proteins are enough to induce an immune response. Nevertheless, during the penetration of the b-lactoglobulin A through the skin, allergenic residues of b-lactoglobulin A could have been created and could have also accumulated in the vicinity of immune cells, thus inducing an immune response. Whatever the mechanism, the clinical results show a clear immune response in the skin when allergen is applied by APT $(1,5,6,13,15 Y 17,31,32)$.

When developing a diagnostic test for allergy, it is important to consider the possibility of systemic delivery of allergen proteins through the skin, which could obviously induce a systemic anaphylactic response. From this point of view, the present study suggested that the passage of blactoglobulin A in native form through the skin was almost non-existent. Indeed, no percutaneous absorption leading to the transfer of allergen across the skin from the external environment as far as to the blood has ever been proved (33). Radioactive material from the patch was shown to cross rat skin over a 24-h period. However, the results obtained after acid precipitation of the receiver phase and by immunoassay and electrophoresis indicate that this radioactivity did not originate from intact protein. Electrophoresis of the radioactive 
mother solution showed that radioactivity in the receiver compartment could be attributed to low-molecular-weight impurities. Analysis by electrophoresis indicated that the radiolabeled solution of b-lactoglobulin A-[methyl-14C] was essentially composed of radiolabeled b-lactoglobulin A monomers and dimers accounting for $96 \%$ of the total of radiolabeled material. However, $4 \%$ of radiolabeled impurities

Fig. 4. b-Lactoglobulin A-[methyl-14C] detected in the 12 first layers of the stratum corneum after iterative stripping. These 12 strips allowed "-lactoglobulin $\mathrm{A}$-[methyl-14C] to be detected in the stratum corneum, which is the first layer of the epidermis and which was in contact with the radiolabeled "-lactoglobulin $(n=3)$. The total amount of "-lactoglobulin A-[methyl-14C] reached $100 \%$ at the end of the experiment after $24 \mathrm{~h}$.

1534 Soury et al.

with a low molecular mass was detected, which likely represented degradation products of b-lactoglobulin A or intermediates of radiolabeled synthesis or contaminants proteins of the lactoserum radiolabeled during the synthesis. These small impurities might be able to cross the skin better than b-lactoglobulin A and be responsible for the radioactivity detected in the receiver compartment.

The absence of b-lactoglobulin A in native form in the receiver compartment is not unexpected because proteins, as large hydrophilic molecules, penetrate the skin barrier poorly. The topical delivery of $\mathrm{IFN}-\mathrm{a}$, a soluble protein with a molecular mass of about $20 \mathrm{kDa}$, similar to that of blactoglobulin, in different formulations has been followed

(30). After $24 \mathrm{~h}$, no IFN-a could be detected in the receiver compartment, whatever the formulation.

Concerning these first results on b-lactoglobulin A, it is important to bear in mind that this study, which could not be performed on infants' skin for obvious ethical reasons, necessitated the use of an in vitro experimental diffusion model. Permeability data about infant's skin are quite poorly documented and no specific in vitro models have been established. On one hand, porcine ear skin has been shown to be a valid model for the human skin barrier by comparing the permeability of marker molecules (34).

Furthermore, porcine ear skin can be differentially tapestripped to mimic the barrier properties of skin in premature neonates (35), known to have higher skin permeability than infants. On the other hand, Fasano et al. (36) have shown that, under infinite dose and occlusive conditions, rat skin permeability was higher than that of human skin. Therefore, as infants' skin permeability is higher than adults' skin permeability but lower than that of premature neonates, rat skin was preferred to tape-stripped porcine ear skin because of its high permeability compared with human skin under experimental conditions close to those adopted in this study (infinite dose and occlusive conditions). Therefore, the results were thought to be relevant to the clinical situation in infants

To summarize, with the E-patch system, the native form of the b-lactoglobulin A could not cross hairless rat skin but putative degradation products of this protein may do so, probably because of their low molecular mass. Therefore, this suggests that only negligible amounts of residues of blactoglobulin A could cross hairless rat skin during the 24

$\mathrm{h}$ after the patch is applied.

b-lactoglobulin A is a good marker of cow's milk allergy.

The study of this model protein demonstrates that the native form of b-lactoglobulin A could not cross the skin but concentrates in the vicinity of immune cells. This result is important because it suggests that the E-patch would probably not promote systemic delivery of intact proteins, thereby reducing the possibility of systemic anaphylactic shocks. This is in agreement with the fact that no incident of 
anaphylactic shock has been described during clinical trials of APT $(1,5,15,31)$.

Therefore, it seems that ideal conditions for promoting a topical response for a positive test to milk proteins are created. This study also gives a first appreciation of the efficacy and the safety of the E-patch system. Nevertheless, cow's milk also contains other major proteins having similar or larger molecular masses: between 20 and $24 \mathrm{kDa}$ for caseins, $14 \mathrm{kDa}$ for a-lactalbumin, and $60 \mathrm{kDa}$ for albumin. Their localization and transdermal delivery through hairless rat skin should be studied to complete our observations. CONCLUSIONS

The E-patch system allows b-lactoglobulin A to concentrate in the stratum corneum, in the vicinity of Langerhans cells and other immunological cells, but does not lead to systemic delivery of intact b-lactoglobulin A. Therefore, it seems to create ideal conditions for milk allergens to promote a topical response for a positive diagnostic test with reduced risk of systemic anaphylactic reactions caused by the native form of the b-lactoglobulin A. ACKNOWLEDGMENTS

This work was supported by the CNRS, UPS, INRACEA, and by DBV Technologies (Boulogne Billancourt, France). The authors would like to thank Dr. Michel Renoir (UMR CNRS 8612) for help with electrophoretic analysis of b-lactoglobulin purity and Dr. Herve Bernard (INRA) for immunodosage. ANRT supported D. Soury (CIFRE). REFERENCES

1. T. Vanto, K. Juntunen-Backman, K. Kalimo, T. Klemola, A. Koivikko, P. Koskinen, P. Syvanen, E. Valovirta, and E. Varjonen. The patch test, skin prick test, and serum milkspecific IgE as diagnostic tools in cow's milk allergy in infants. Allergy 54:837Y842 (1999).

2. J. M. Wal. Cow's milk proteins/allergens. Ann. Allergy, Asthma \& Immun. 89:3Y10 (2002).

3. S. A. Bock, H. A. Sampson, F. M. Atkins, R. S. Zeiger,

S. Lehrer, M. Sachs, R. K. Bush, and D. D. Metcalfe. Doubleblind, placebo-controlled food challenge (DBPCFC) as an office procedure: amanual. J. Allergy Clin. Immunol. 82:986Y997 (1988). 4. L. Rasanen, M. Lehto, and T. Reunala. Diagnostic value of skin and laboratory tests in cow's milk allergy/intolerance. Clin. Exp. Allergy 22:385Y390 (1992).

5. E. Isolauri and K. Turjanmaa. Combined skin prick and patch testing enhances identification of food allergy in infants with atopic dermatitis. J. Allergy Clin. Immunol. 97:9Y15 (1996). 6. C. C. Roehr, S. Reibel, M. Ziegert, C. Sommerfeld, U. Wahn, and B. Niggemann. Atopy patch tests, together with determination of specific IgE levels, reduce the need for oral food challenges in children with atopic dermatitis. J. Allergy Clin. Immunol. 107:548Y553 (2001).

7. C. Dupont and D. de Boissieu. Milk and atopy. Rev. Fr. Allergol. Immunol. Clin. 42:574Y582 (2002).

8. D. Jaffuel, P. Demoly, and J. Bousquet. Food allergies. Rev. Fr. Allergol. Immunol. Clin. 41:169Y186 (2001).

9. D. Schmitt. Cutaneous immune system. C. R. Seances Soc. Biol. Fil. 188:207Y221 (1994).

10. I. Kimber and M. Cumberbatch. Dendritic cells and cutaneous immune responses to chemical allergens. Toxicol. Appl. Pharmacol. 117:137Y146 (1992).

11. N. Novak, J. Haberstok, E. Geiger, and T. Bieber. Dendritic cells in allergy. Allergy 54:792Y803 (1999).

12. B. Niggemann, S. Reibel, and U. Wahn. The atopy patch test (APT)Ya useful tool for the diagnosis of food allergy in children with atopic dermatitis. Allergy 55:281Y285 (2000).

13. D. De Boissieu, J. C. Waguet, and C. Dupont. The atopy patch tests for detection of cow's milk allergy with digestive symptoms. J. Pediatr. 142:203Y205 (2003)

14. J. J. Berti and J. J. Lipsky. Transcutaneous drug delivery: a practical review. Mayo Clin. Proc. 70:581Y586 (1995).

15. O. M. Kekki, K. Turjanmaa, and E. Isolauri. Differences in Skin Localization of Cow's Milk Proteins 1535

skin-prick and patch-test reactivity are related to the heterogeneity 
of atopic eczema in infants. Allergy 52:755Y759 (1997).

16. H. Majamaa, P. Moisio, K. Holm, H. Kautiainen, and K.

Turjanmaa. Cow's milk allergy: diagnostic accuracy of skin prick

and patch tests and specific IgE. Allergy 54:346Y351 (1999).

17. L. Stromberg. Diagnostic accuracy of the atopy patch test and the skin-prick test for the diagnosis of food allergy in young children with atopic eczema/dermatitis syndrome. Acta Paediatr. 91:1044Y1049 (2002).

18. E. Berardesca, G. P. Vignoli, D. Fideli, and H. Maibach. Effect of occlusive dressings on the stratum corneum water holding capacity. Am. J. Med. Sci. 304:25Y28 (1992).

19. T. Agner and J. Serup. Time course of occlusive effects on skin evaluated by measurement of transepidermal water loss

(TEWL). Including patch tests with sodium lauryl sulphate and water. Contact Dermatitis 28:6Y9 (1993).

20. T. M. Keahey, K. B. Yancey, and T. J. Lawley. Immediate hypersensitivity. J. Am. Acad. Dermatol. 17:826Y837 (1987). 21. J. M. Wal. Structure and function of milk allergens. Allergy 56(Suppl 67):35Y38 (2001).

22. T. N. Koritz, S. Suzuki, and R. R. Coombs. Antigenic stimulation with proteins of cow's milk via the oral route in guinea pigs and rats. 1. Measurement of antigenically intact beta-lactoglobulin and casein in the gastrointestinal contents of duodenum, jejunum and ileum. Int. Arch. Allergy Appl. Immunol. 82:72Y75 (1987).

23. L. Negroni, H. Bernard, G. Clement, J. M. Chatel, P. Brune, Y. Frobert, J. M. Wal, and J. Grassi. Two-site enzyme immunometric assays for determination of native and denatured betalactoglobulin. J. Immunol. Methods 220:25Y37 (1998).

24. D. Dottavio-Martin and J. M. Ravel. Radiolabeling of proteins by reductive alkylation with $[14 \mathrm{C}]$ formaldehyde and sodium cyanoborohydride. Anal. Biochem. 87:562Y565 (1978). 25 . W. A. Ritschel. In vivo animal models for bioavailability assessment. STP Pharma 3:125Y141 (1987)

26. C. D. Partidos, A. S. Beignon, F. Brown, E. Kramer, J. P. Bri, and S. Muller. Applying peptide antigens onto bare skin: induction of humoral and cellular immune responses and potential for vaccination. J. Control. Release 85:27Y34 (2002). 27. G. M. Glenn, T. Scharton-Kersten, R. Vassell, C. P. Mallett, T. L. Hale, and C. R. Alving. Transcutaneous immunization with cholera toxin protects mice against lethal mucosal toxin challenge. J. Immunol. 161:3211Y3214 (1998).

28. S. A. Hammond, D. Walwender, C. R. Alving, and G. M. Glenn Transcutaneous immunization: $\mathrm{T}$ cell responses and boosting of existing immunity. Vaccine 19:2701Y2707 (2001).

29. J. M. Spergel, E. Mizoguchi, J. P. Brewer, T. R. Martin, A. K.

Bhan, and R. S. Geha. Epicutaneous sensitization with protein antigen induces localized allergic dermatitis and hyperresponsiveness to methacholine after single exposure to aerosolized antigen in mice. J. Clin. Invest. 101:1614Y1622 (1998) 30. K. Egbaria, C. Ramachandran, D. Kittayanond, and N. Weiner. Topical delivery of liposomally encapsulated interferon evaluated by in vitro diffusion studies. Antimicrob. Agents Chemother. 34:107Y110 (1990).

31. B. Niggemann. Atopy Patch Test (APT)Vits role in diagnosis of food allergy in atopic dermatitis. Indian J. Pediatr. 69:57Y59 (2002).

32. K. Perackis, S. Celik-Bilgili, U. Staden, A. Mehl, and B.

Niggemann. Influence of age on the outcome of the atopy patch test with food in children with atopic dermatitis. J. Allergy Clin Immunol. 112:625Y627 (2003).

33. F. Berard, J. P. Marty, and J. F. Nicolas. Allergen penetration through the skin. Eur. J. Dermatol. 13:324Y330 (2003).

34. N. Sekkat, Y. N. Kalia, and R. H. Guy. Biophysical study of porcine ear skin in vitro and its comparison to human skin in vivo. J. Pharm. Sci. 91:2376Y2381 (2002).

35. N. Sekkat, Y. N. Kalia, and R. H. Guy. Porcine ear skin as a model for the assessment of transdermal drug delivery to premature neonates. Pharm. Res. 21:1390Y1397 (2004). 36. W. J. Fasano, G. L. Kennedy, B. Szostek, D. G. Farrar, R. J. Ward, L. Haroun, and P. M. Hinderliter. Penetration of ammonium perfluorooctanoate through rat and human skin in vitro. Drug Chem. Toxicol. 28:79Y90 (2005)

1536 Soury et a1. 